\title{
Bioética: pensando e embasando o diálogo entre saúde e sociedade, na contemporaneidade
}

\author{
Bioethics: conceiving and backing dialogue between health and \\ contemporary society
}

\author{
Bioética: pensando y fundamentando el diálogo entre salud y \\ sociedad, en la contemporaneidad
}

BIOETICA, SAÚDE E SOCIEDADE. Palacios M, organizadora. Rio de Janeiro: Editora Fiocruz; 2019. 210 p. ISBN 978-85-7541-635-8.

doi: 10.1590/0102-311X00014720

Começando pelo título, o livro Bioética, Saúde $e$ Sociedade vem cumprir aquilo a que se propõe - dialogar com a sociedade na construção das condutas ancoradas nos costumes e valores comunitários, que é uma forma prática de pensar a bioética. O livro não é "mais do mesmo" - não discute as mesmas questões dos primórdios da disciplina, nos anos 1960-1970. Nele, encontram-se trabalhos de pesquisadores nacionais, de diferentes localidades, que vêm produzindo conhecimento na área; da medicina, direito e também de farmácia, ciências sociais, dentre outras.

Assim, já no primeiro capítulo tem-se uma dissertação cujo tema é pedofilia. Choca! E é para tanto, atrai. Começa inclusive pela estupefação da autora frente a um caso real. O título, autoexplicativo, coloca a pedofilia entre o crime e a loucura. Faz-se um retrato não neutro, porque contrário, porém isento, de como ocorre o "dobramento" penal-psiquiátrico, transformando uma categoria classificatória da psiquiatria, a pedofilia, em questão e terminologia jurídicas. Aos que se interessam pelo assunto o livro O Monstro Contemporâneo 1 é uma sugestão de leitura.
O segundo capítulo traz ampla introdução à bioética para saúde pública. Criticando o Principalismo, é na Bioética da Proteção que os autores encontram oposição ao biopoder e biopolítica incorporados à "intolerante e autoritária" Estratégia Saúde da Família (ESF). De fato, a literatura nos apresenta a polêmica entre a proposta de valorizar o cuidado no contexto da vida privada e o risco de reafirmar relações de poder nas práticas de saúde. Caberia à ESF garantir às pessoas condições de desenvolver suas capacidades. Infelizmente, essa visão singular de crítica à ESF aparece abreviada, respondendo por 4 das 27 páginas do capítulo. Importante seria uma discussão aprofundada, para não obscurecer os resultados positivos da estratégia destacados em recente revisão 2 .

Talvez porque tenha o método como escopo, o capítulo 3 aborda o tema das métricas em saúde pública valendo-se das definições e aprofundando-se nas questões éticas para sugerir ações e pesquisas do campo. As medidas-sumário descrevem a saúde das populações e subsidiam decisões de alocação de recursos. Se se vivencia a transição epidemiológica com aumento de doenças crônicas e no nosso meio de pobreza e desigualdade enfrentam-se as doenças negligenciadas, precisa-se também, sugere a autora, uma "profunda transição metodológica" para coletar, sistematizar e interpretar dados. A carga global de doença, principal métrica da Organização Mundial da Saúde (OMS), deve ser repensada e a construção de novas modelagens não pode ba- 
sear-se em custo-efetividade, de forma utilitarista. Devem ser considerados valores individuais e dos grupos, assim como os valores do SUS, embasados na teoria das capacidades de Sen 3.

Ainda tendo em conta o Brasil como o 10o maior em desigualdades sociais, incorrendo em mais sofrimento aos já vulnerados na área da saúde, o capítulo 4 é uma exortação à formação em direitos humanos. São apresentados os Programas Mundial e Nacional de Educação em direitos humanos, implicando disciplinas nas faculdades e fomento à pesquisa. Os autores, porém, apontam barreiras à proposta no modelo tecnicista biomédico. Na verdade, existem na literatura questionamentos à própria fundamentação moral dos direitos humanos, sendo interessante o texto de Maximo 4, que faz um comparativo entre a abordagem deontológica e a aristotélica, em favor da última. A abordagem grega também foi defendida por Pellegrino 5 para educação em humanidades médicas - não obrigar ninguém a um dever, mas partir da disposição ao agir virtuoso e seguindo exemplos de conduta, na prática.

O capítulo 5 apresenta uma proposta de criação de Comissão de Bioética para atenção primária em saúde no Município do Rio de Janeiro. Tem dois embasamentos: a importância das comissões existentes no contexto clínico hospitalar e a especificidade da atenção primária, com eixos de conflitos nas relações com usuários, entre equipes e com a gestão. Os autores recomendam a participação dos conselhos municipais distritais e sugerem os passos para criação da comissão: sensibilização do corpo social local, elaboração de regimento (composição multidisciplinar, organização e funcionamento) e educação profissional.

Na sequência, a organizadora Marisa Palácios e Sérgio Rego, pioneiros do ensino e pesquisa em Bioética no Brasil, apresentam um abrangente ensaio sobre Integralidade em pesquisa. A confiabilidade nos resultados depende da responsabilidade (accountability) dos agentes e instituições, na condução e comunicação da pesquisa.

O capítulo 7 aborda os dilemas éticos nas emergências sanitárias - desastres, epidemias. Didático, define que eles ocorrem quando se excede a capacidade de superação da comunidade; entre vulnerabilidade e resiliência. Qual o papel do "Estado protetor" aos vulnerados e à coletividade? Estar preparado e estabelecer prioridades, evitando excesso de autoridade. Há críticas ao principialismo, incluindo uma referência interessante sobre as limitações da cultura da "autonomia”, assim como ao utilitarismo, classificado como "teoria de justiça fragilizada". Ao contrário, a Bioética da Intervenção é proposta por considerar a maioria, respeitando direitos individuais e equidade. Independentemente do Estado, há um apelo da sociedade aos profissionais de saúde, comprometidos ética e tecnicamente. Conclui-se pela capacitação visando à sensibilização, ao invés do cumprimento de regras.

Aprofundando o tema da tomada de decisão nas epidemias, pode-se dizer que o último capítulo faz um fechamento do anterior e de ideias que permeiam todo o livro. Decisões não podem ser apenas técnicas, mas valorativas! Interesses coletivos não combinam com a exagerada ênfase contemporânea na autonomia 6 . Ao Estado cabe cuidar e proteger, o que significa também oferecer condições sociais aos indivíduos e de trabalho aos profissionais expostos a agentes perigosos. Resta a pergunta: o que é obrigatório, o que é virtuoso?

Este capítulo, ilustrado pelo caso da epidemia de Ebola, me remeteu ao livro A Peste 7, do Nobel de literatura Camus - história de uma epidemia de peste bubônica utilizada para refletir sobre a 2a Guerra Mundial. Não há melhor descrição do papel dos profissionais de saúde e da sociedade no enfrentamento das condições de doença, isolamento, vulnerabilidade; revelando assim a natureza da condição humana... Vale a leitura!

Também vale a leitura da coletânea Bioética, Saúde e Sociedade. Aos iniciantes no campo, o livro oferece muitos trechos de revisão, nas introduções, e relevante bibliografia em cada capítulo (apesar de dois ou três trazerem elevado índice de autocitações!). Os que desejam aprofundamento, certamente encontrarão.

Patricia Souza Valle Cardoso Pastura 1

1 Fundação Oswaldo Cruz, Rio de Janeiro, Brasil.

patpastura@gmail.com 


\section{Informação adicional}

ORCID: Patricia Souza Valle Cardoso Pastura (0000-0001-7198-1481).

\section{Referências}

1. Lowenkron L. O monstro contemporâneo: a construção social da pedofilia em múltiplos planos. Rio de Janeiro: EdUERJ; 2015.

2. Macinko J, Mendonça CS. Estratégia Saúde da Família, um forte modelo de atenção primária à saúde que traz resultados. Saúde Debate 2018; 42:18-37.

3. Sen A. Development as freedom. New York: Anchor Press; 2000.

4. Máximo M. Os direitos humanos e a alternativa da ética das virtudes. Anais de Filosofia Clássica 2015; 9:75-105.

5. Pellegrino ED. The humanities in medical education: entering the post-evangelical era. Theor Med 1984; 5:253-66.

6. O'Shea T. Critics of autonomy. Green paper technical report. The Essex Autonomy Project, 2012. http://autonomy.essex.ac.uk/re sources/critics-of-autonomy/ (acessado em 20/ Dez/2019).

7. Camus A. A peste. Rio de Janeiro: Best Bolso; 2011. 